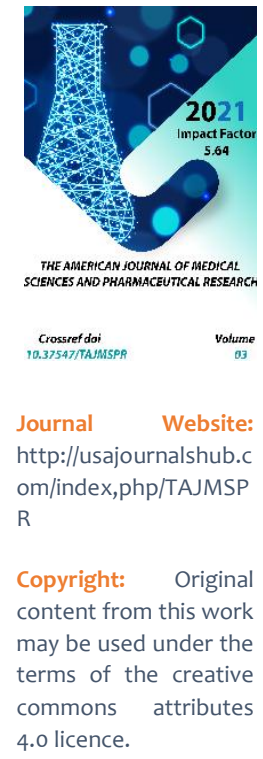

\title{
Features Of Change In Indicators Of Micro- And Macroelement Status Of The Organism In Women Of Fertilized Age With Anemia Of Iron Deficiency
}

\author{
Akhmedova Nilufar Sharipovna \\ Bukhara State Medical Institute, Uzbekistan \\ Sokhibova Ziyoda Rakhmonovna \\ Bukhara State Medical Institute, Uzbekistan \\ Ulugova Shakhlo Turaevna \\ Bukhara State Medical Institute, Uzbekistan
}

\section{ABSTRACT}

Using unified and developed methods, some hematological, biochemical and indicators of the microand macroelement status of the body in Bukhara women of fertile age with a normal hemoglobin health index and iron deficiency have been studied. It has been shown that there are certain pathological fluctuations in some hematological, biochemical and essential hematopoietic microelements in women of fertile age when they develop an iron deficiency state. In particular, there is hypoproteinemia, hypoferremia, hypocincemia, hypocuremia, and hypertransferrinemia. This phenomenon can be used to monitor the state of hemoglobin health in women of fertile age.

\section{KEYWORDS}

Iron deficiency states, fertile age, micro and macro elements.

\section{INTRODUCTION}

Iron deficiency states - latent and manifest iron deficiency have a high prevalence in various regions of the country and, in general, significantly exceed the critical threshold level of $30 \%$ of the population, when the implementation of national programs for mass 
prevention and control of anemia is required $[1,2,3]$.

As we noted above, one of the main reasons for the development and widespread prevalence of iron deficiency anemia (IDA) among women of fertile age (IRF) is nutritional iron deficiency. At the same time, as practice shows in real life, i.e. in the clinic of diseases, disorders of normal development, the conditions for the occurrence of any monodeficiencies simply do not exist (4). Even if one can imagine the presence of such a deficiency, for example, an iodine deficiency in an endemic territory, then very soon the monodeficiency state will interfere with the assimilation and metabolism of other nutrients and the monodeficiency will necessarily turn into a group or complex one. With regard to iron deficiency, according to the literature, a parallel identification of insufficient provision for other microelements, vitamins C, PP, B6, folic acid, and vitamin B12 is revealed quite naturally $[4]$.

Due to this, the cooperative study of various nutrients, primarily those directly related to hematopoiesis, acquires important scientific and practical significance.

The aim of this work was to study a number of biochemical parameters in healthy women of fertile age and women with iron deficiency (ID).

\section{MATERIAL AND METHODS}

In order to characterize the biochemical status of the body of healthy women of fertile age with normal hemoglobin health, 48 women aged 20 to 35 years (average age 23.6 years) and 46 women with iron deficiency (ID) aged 20 to 40 years (average age - 31.7 years) permanently residing in the Gijduvan fog of the Bukhara region. The studied hematological and biochemical parameters were determined by unified methods, as described [5]. Micro- and macroelement status of the organism LPV was analyzed using quantitative colorimetric methods. The results were processed by methods of variation statistics.

\section{RESULTS AND DISCUSSION}

The results are shown in table 1.

Table 1

\begin{tabular}{|c|c|c|}
\hline Studied indicator & LPV healthy & Iron-deficient LPV \\
\hline Hemoglobin, g/I & $120.0-143.0$ & $98.0-118.0$ \\
\cline { 2 - 3 } & $(128.6 \pm 1.04)$ & $(110.8 \pm 1.01)$ \\
\hline Erythrocytes, $\times 10^{12} / 1$ & $3.1-4.4$ & $3.4-5.0$ \\
\hline Leukocytes, $\times 10^{9} / 1$ & $(3.9 \pm 0.04)$ & $(4.0 \pm 0.05)$ \\
\hline
\end{tabular}


The American Journal of Medical Sciences and Pharmaceutical Research

(ISSN - 2689-1026)

Published: April 30, 2021 | Pages: 200-205

IMPACT FACTOR

Doi: https://doi.org/10.37547/TAJMSPR/Volume03Issue04-29

2021: 5.64

OCLC - 1121105510

\begin{tabular}{|c|c|c|}
\hline & $(5.6 \pm 0.36)$ & $(5.0 \pm 0.32)$ \\
\hline \multirow[t]{2}{*}{ Platelets, x $10^{9} / \mathrm{I}$} & $200.0-275.0$ & $200.0-275.0$ \\
\hline & $(240.6 \pm 4.56)$ & $(218.0 \pm 4.12)$ \\
\hline \multirow[t]{2}{*}{ Color indicator } & $0.81-1.1$ & $0.70-0.90$ \\
\hline & $(0.96 \pm 0.01)$ & $(0.80 \pm 0.01)$ \\
\hline \multirow[t]{2}{*}{ Bilirubin, $\mu \mathrm{mol} / \mathrm{I}$} & $8.9-14.3$ & $9.0-12.3$ \\
\hline & $(11.4 \pm 0.21)$ & $(10.8 \pm 0.15)$ \\
\hline \multirow[t]{2}{*}{ Total protein, g/l } & $67.0-85.0$ & $60.0-72.0$ \\
\hline & $(75.3 \pm 0.93)$ & $(65.8 \pm 0.56)$ \\
\hline \multirow[t]{2}{*}{ AlT, $\mu \mathrm{mol} / \mathrm{L}$} & $13.0-28.0$ & $11.0-36.0$ \\
\hline & $(19.6 \pm 0.55)$ & $(18.3 \pm 0.86)$ \\
\hline \multirow[t]{2}{*}{ AsT, $\mu \mathrm{mol} / \mathrm{L}$} & $15.3-28.3$ & $16.6-31.0$ \\
\hline & $(21.5 \pm 0.53)$ & $(22.6 \pm 0.65)$ \\
\hline \multirow[t]{2}{*}{ Iron, $\mu \mathrm{mol} / \mathrm{I}$} & $13.6-25.6$ & $8.7-13.9$ \\
\hline & $(18.0 \pm 1.18)$ & $(11.5 \pm 0.24)$ \\
\hline \multirow[t]{2}{*}{ Zinc, $\mu \mathrm{mol} / \mathrm{I}$} & $14.1-25.9$ & $9.4-15.6$ \\
\hline & $(19.4 \pm 0.47)$ & $(13.3 \pm 0.21)$ \\
\hline \multirow[t]{2}{*}{ Copper, $\mu \mathrm{mol} / \mathrm{I}$} & $10.2-19.0$ & $6.4-12.4$ \\
\hline & $(14.9 \pm 0.35)$ & $(9.3 \pm 0.30)$ \\
\hline \multirow[t]{2}{*}{ Calcium, mmol / I } & $1.97-2.74$ & $1.16-2.20$ \\
\hline & $(2.59 \pm 0.13)$ & $(2.50 \pm 0.03)$ \\
\hline
\end{tabular}


The American Journal of Medical Sciences and Pharmaceutical Research

(ISSN - 2689-1026)

IMPACT FACTOR

Published: April 30, 2021 | Pages: 200-205

2021: 5.64

Doi: https://doi.org/10.37547/TAJMSPR/Volume03Issue04-29

OCLC - 1121105510

\begin{tabular}{|c|c|c|}
\hline Magnesium, $\mu \mathrm{mol} / \mathrm{I}$ & $0.50-1.15$ & $0.61-1.10$ \\
\cline { 2 - 3 } & $(0.765 \pm 0.02)$ & $(0.755 \pm 0.015)$ \\
\hline Transferrin, g/I & $3.00-3.60$ & $3.65-4.24$ \\
\cline { 2 - 3 } & $(3.27 \pm 0.01)$ & $(3.97 \pm 0.03)$ \\
\hline CST,\% & $15.3-34.6$ & $8.0-15.5$ \\
\hline & $(22.6 \pm 0.71)$ & $(11.9 \pm 0.34)$ \\
\hline
\end{tabular}

As can be seen from the presented table, in healthy LPV, the total hemoglobin index averaged $128.6 \pm 1.04 \mathrm{~g} / \mathrm{L}$ with the range of fluctuations of this indicator from $120.0 \mathrm{~g} / \mathrm{L}$ (min) to $143.0 \mathrm{~g} / \mathrm{L}$ (max). In LPV with ID, the average level of total hemoglobin was significantly $(p<0.001)$ lower and

was $110.8 \pm 1.01 \mathrm{~g} / \mathrm{L}$ with the range of fluctuations of this indicator $-98.0 \mathrm{~g} / \mathrm{L}(\mathrm{min})$ to $118.0 \mathrm{~g} / \mathrm{L}(\max )$.

We did not find a statistically significant difference between other morphological parameters of peripheral blood in the examined healthy LPV and LPV with ID-number of leukocytes and platelets ( $p>0.05)$.

As expected, there is a statistically significant difference between such an important indicator as a color indicator reflecting hypochromia in the examined healthy LPV and LPV with ID. Thus, in healthy LPV this indicator averages $0.96 \pm 0.01$ with the range of fluctuations of this indicator from $0.81(\mathrm{~min})$ to 1.1 (max), whereas in LPV with ID this indicator on average is only $0.80 \pm 0.01$ with the range of fluctuations of this indicator from $0.80(\mathrm{~min})$ to $0.90(\max )(p<0.001)$.
The study of biochemical parameters reflecting the functional state of the liver of

the examined healthy LPV and LPV with ID showed that LPV with ID has bilirubinemia and hypoproteinemia as compared with healthy LPV. Thus, on average, the content of bilirubin in the examined LPVs with ID was $10.8 \pm 0.86$ $\mu \mathrm{mol} / \mathrm{L}$ with a range of fluctuations of this indicator from $9.0 \mu \mathrm{mol} / \mathrm{L}$ (min) to $12.3 \mu \mathrm{mol} /$ $L$ (max), while in normal conditions this indicator averaged $11.4 \pm 0.21 \mu \mathrm{mol} / \mathrm{L}$ with a range of fluctuations of this indicator from 8.9 $\mu \mathrm{mol} / \mathrm{L}(\min )$ to $14.3 \mu \mathrm{mol} / \mathrm{L}(\max )(\mathrm{p}<0.05)$.

The level of total protein in the blood serum of the examined LFV with ID was on average only $65.8 \pm 0.56 \mathrm{~g} / \mathrm{L}$, with the range of fluctuations of this indicator in the examined women $60.0 \mathrm{~g}$ / L ( $\min )$ to $72.0 \mathrm{~g} / \mathrm{L}(\max )$, which indicates the phenomenon of hypoproteinemia in ZhFV with $J$. The average level of total protein in healthy examined LPV averages $75.3 \pm 0.93 \mathrm{~g} / \mathrm{L}$ with the range of fluctuations of this biochemical indicator from $67.0 \mathrm{~g} / \mathrm{L}(\mathrm{min})$ to $85.0 \mathrm{~g} / \mathrm{L}$ $(\max )(p<0.001)$.

Comparative analysis of blood serum enzyme indices in healthy LPV and LPV with ID did not 
reveal statistically significant differences between them $(p>0.05)$.

Analysis of the trace element status in healthy LPV and LPV with ID showed clear hypoferremia, hypocinemia and hypocupremia in LPV with ID. Thus, the level of serum iron in LFV with ID is significantly reduced on average to $11.5 \pm 0.24 \mu \mathrm{mol} / \mathrm{L}$ with a range of fluctuations of this indicator from $8.7 \mu \mathrm{mol} / \mathrm{L}$ (min) to $13.9 \mu \mathrm{mol} / \mathrm{L}$ (max) in comparison with the level of serum iron in healthy subjects. LPVon average $18.0 \pm 1.18 \mu \mathrm{mol} / \mathrm{L}$ with the range of fluctuations of this indicator from $13.6 \mu \mathrm{mol}$ / L (min) to $25.6 \mu \mathrm{mol} / \mathrm{L}(\max )(\mathrm{p}<0.001)$. In LFV with ID, the level of serum zinc is also significantly reduced, on average, to a level of $13.3 \pm 0.21 \mu \mathrm{mol} / \mathrm{L}$ with the range of fluctuations of this indicator from $9.4 \mu \mathrm{mol} / \mathrm{L}$ (min) to $15.6 \mu \mathrm{mol} / \mathrm{L}(\max )$ compared to the level of zinc in the blood serum in healthy LPV on average $19.4 \pm 0.47 \mu \mathrm{mol} / \mathrm{L}$ with the range of fluctuations of this indicator from $14.1 \mu \mathrm{mol}$ / L (min) to $25.9 \mu \mathrm{mol} / \mathrm{L}$ (max) ( $\mathrm{p}<0.001)$.

The level of another essential hematopoietic trace element copper in LPV with ID is also reduced in comparison with that in healthy LPV. Thus, on average, in LPV with ID, the serum copper level is $9.3 \pm 0.3 \mu \mathrm{mol} / \mathrm{L}$ with the range of fluctuations of this indicator from 6.4 $\mu \mathrm{mol} / \mathrm{L}$ ( $\min$ ) to $12.4 \mu \mathrm{mol} / \mathrm{L}$ (max), while in healthy LPV the level of serum copper is on average is $-14.9 \pm 0.35 \mu \mathrm{mol} / \mathrm{L}$ with a range of fluctuations of this indicator from $10.2 \mu \mathrm{mol} / \mathrm{L}$ (min) to $19.0 \mu \mathrm{mol} / \mathrm{L}(\max )(\mathrm{p}<0.001)$.

Comparative analysis of the content of essential hematopoietic microelements in LPV allows us to conclude that, on average, the level of zinc in the blood serum prevails over the level of iron, and the level of both zinc and iron prevails over the level of copper in the blood serum.
In the content of another trace element magnesium, we did not reveal statistically significant differences between healthy LPV and LPV with ID ( $p>0.05)$.

The content of an important macronutrient calcium in blood serum also did not reveal significant differences in the content of this macronutrient ( $p>0.05)$.

Hypertransferrinemia is a characteristic phenomenon for LPV with ID. compensatory increase in the content of iron transport protein in the blood serum against the background of hypoferremia. Thus, on average, the content of this protein in the blood serum of LFV with ID is $3.65 \pm 0.03 \mathrm{~g} / \mathrm{L}$ with a range of fluctuations of this indicator from $3.65 \mathrm{~g} / \mathrm{L}(\mathrm{min})$ to $4.24 \mathrm{~g} / \mathrm{L}$ (max), while in healthy LFV this indicator is averages $3.27 \pm$ $0.01 \mathrm{~g} / \mathrm{L}$ with the range of fluctuations of this indicator from $3.00 \mathrm{~g} / \mathrm{L}(\mathrm{min})$ to $3.60 \mathrm{~g} / \mathrm{L}$ $(\max )(\mathrm{p}<0.001)$.

The saturation of the total pool of serum transferrin with iron in LPV with ID is clearly reduced and averages only $11.9 \pm 0.34 \%$ with the range of fluctuations of this indicator from $8.0 \%$ (min) to $15.5 \%$ ( $\max$ ), while in healthy LPV the transferrin saturation index with iron on average is $22.6 \pm 0.71 \%$ with the range of fluctuations of this indicator from $15.3 \%$ ( $\mathrm{min}$ ) to $34.6 \%(\max )(p<0.001)$.

\section{CONCLUSION}

Thus, a comparative study of some hematological, biochemical parameters and indicators of the micro- and macroelement status of the organism of LPI shows that the development of ID in the body objectively leads to significant changes in some indicators reflecting the state of hematopoiesis, the functional state of the liver, as well as the microelement status of the organism. This 
phenomenon can be used in monitoring the state of the LPV organism, in monitoring the effectiveness of the measures taken in these women against the background of developing ID in them.

\section{REFERENCES}

1. Suleimanova D.N. Supplementation program with iron and folic acid in risk groups. Methodical guidance. Tashkent. - 2004. [in russian]

2. Boltaev K.Zh., Akhmedova N.Sh. Characteristics of the phenomenon of the development of polydeficiency states during aging // Problems of Biology and Medicine. - 2020. No. 1. Tom. 116 .-- S. 24-26. [in russian]

3. Akhmedova N.Sh., Boltaev K.Zh., Egamova S.K, Ismatova M.N. A comprehensive study of the metabolism of some trace elements in women of fertile age with anemia // Pediatric Bulletin of the Southern Urals, 2015. No. 2. P. 14-16. [in russian]

4. Ibragimova M.Ya., Sabirova L.Ya. Influence of cyclophosphamide on the balance of macro- and microelements and indicators of lipid peroxidation // Bulletin of Restorative Medicine, 2013. No. 2. P. 70-74. [in russian]

5. Boltaev K.Zh., Akhmedova N.Sh. Development of medical technology for the prevention and treatment of polydeficiency conditions in elderly and senile age: Monograph // Tashkent: Navruz Publishing House, 2016.104 p. [in russian]

6. Boltaev K.Zh., Zharylkasynova G.Zh., Giyazova M.M. Features of the development of nutritional deficiency anemias in the elderly in comparison with young age // Problems of Biology and Medicine, 2016. No. 3, 1. P. 25-26. [in russian] 